\title{
Experimental Investigation on Concrete with E-waste - A Way to Minimize Solid Waste Deposition
}

\author{
P. Muthupriya $†$ and B. Vignesh Kumar \\ Department of Civil Engineering, N.G.P. Institute of Technology, Coimbatore-641 048, T.N., India \\ $\dagger$ Corresponding author: P. Muthupriya; drmuthupriya@gmail.com
}

Nat. Env. \& Poll. Tech.

Website: www.neptjournal.com

Received: 07-09-2020

Revised: $05-11-2020$

Accepted: 08-12-2020

Key Words:

E-waste

Coarse aggregate

Solid waste

Strength properties

\begin{abstract}
In recent years, the generation of Electronic waste (E-waste) has increased to a greater extent worldwide. The use of electronic devices has proliferated in recent decades and proportionality, and the quantity of electronic devices that are disposed of is growing rapidly throughout the world. Electronic waste (E-waste) typically includes general household electronics, discarded electronic gadgets, and circuit boards. With the growing use of consumer electronics, there is a huge generation of E-waste every day. Reuse of E-waste plastics as aggregates or filler in some or other forms of in construction industry may be considered as economical and technically viable for solving the disposal of a large amount of waste and this can be used as aggregates and fine filler in concrete or the construction of flexible pavement. The idea was to determine whether E-waste plastic components can be used as an alternative to conventional material like bitumen, filler in the bituminous mix in a flexible pavement structure. This is an effective alternative solution to reduce the growing quantity of E-waste.
\end{abstract}

\section{INTRODUCTION}

Electronic and electrical waste, commonly known as E-waste items, do not disintegrate or degenerate. The blasting use of electronic and electrical equipment has made another yet extremely hazardous stream of waste, called "electronic-waste", or basically known as e-waste. Used electronics which are sorted for reuse, resale, salvage, recycling, or disposal are also considered e-waste.

On one hand, the development of electronics products has made life easy for all but on the other hand, it has encouraged the "use and throw" mentality. Nowadays people prefer to buy a new appliance rather than taking the pains to get the old appliance repaired. Such a trend not only leads to an increase in the volume of electrical and electronic waste but also poses a serious threat to public health and the environment. E-waste is growing exponentially in recent years because the markets for these products are also growing rapidly. E-waste is presently one of the quickest developing waste streams.

Consistently, countless old PCs, cellular telephones, TV sets, and radio gear are tossed, a large portion of which is either disposed of in landfills or unapproved reusing yards. Informal processing of electronic waste in developing countries may cause serious health and pollution problems, as these countries have limited regulatory oversight of e-waste processing.

The problem of disposing and managing solid waste materials in all countries has become one of the major environmental, economical, and social issues. A complete waste management system including source reduction, reuse, recycling, land-filling, and incineration needs to be implemented to control the increasing waste disposal problems. Typically e-plastics are not recycled into the same type of plastic products made from recycled plastics that are often not recyclable. The use of biodegradable plastics is increasing. If some of these get mixed in the other plastics for recycling, the reclaimed plastic is not recyclable because of the variance in properties and melt temperatures.

\section{PAST STUDIES}

Kaniskha et al. (2019) studied the concrete mixes of various percentages of e-waste. disposal of a large amount of E-waste material, reuse of E-waste in the concrete industry is considered as the most feasible application. The work was conducted on M30 concrete. The replacement of coarse aggregate with E-waste in the range of $0 \%, 5 \%, 10 \%$, $15 \%, 20 \%$ and $25 \%$. Finally, the mechanical properties of the concrete mix specimens obtained from the addition of these materials are compared with the control concrete mix. The test results showed that a significant improvement in compressive strength was achieved in the e-waste concrete compared to conventional concrete and can be used effectively in concrete. Balasubramaniam et al. (2018) carried experimental investigation on e-waste. They have confirmed that no major changes are found in the compressive strength of concrete with the presence of e-plastic. However, when 
$1 \%$ of e-plastic for $5 \mathrm{~cm}$ is added, the compressive strength gets reduced by $2.59 \%$ when compared to the control mix. With the addition of the e-plastic- $4 \mathrm{~cm}$ and e-Plastic- $3 \mathrm{~cm}$, the compressive strength increases to a maximum of 5.9\% and $10.6 \%$ respectively when compared to the control mix. In addition, they have confirmed that an increase in strength is found in the tensile strength of concrete with the presence of e-plastic. When $1 \%$ of the e-plastic for $5 \mathrm{~cm}$ is added, the tensile strength gets increased by $2.3 \%$; when $1 \%$ of the e-plastic for $4 \mathrm{~cm}$ is added, the strength increase observed is $4.6 \%$, and when $1 \%$ of e-plastic for $3 \mathrm{~cm}$ is added, the tensile strength initially increases by $4.6 \%$ when compared to control mix at 28 days of curing and then decreases with the percentage increase. Thus, they have concluded that strength was achieved in the e-plastic concrete compared to conventional concrete.

Raut et al. (2018) observed that the coarse aggregate can be replaced by e-waste and the research strongly showed the possibility of e-waste being used as a substitute for fine and coarse aggregate. More use of this waste material tends to reduce the demand for natural resources used in concrete and it is of prime importance that a substitute of coarse aggregate can be explored. Manjunath (2017) conducted an experimental investigation on concrete with e-waste and reported that by adding various ratios of e-waste in M20 grade concrete, its compressive strength, tensile strength, and flexural strength are tested. The use of e-waste products in concrete not only makes it economical but also helps in reducing disposal problems. Total replacement of concrete is not possible because no material plays the role of concrete in terms of strength, durability, and workability.

Akram (2017) observed that the strength was decreased on the addition of e-waste and hence $10 \%$ fly ash was added. It is reported that the addition of e-waste in concrete will reduce the value of landfill cost and saving energy. It will protect the environment from solid waste pollutions and its effects indirectly. The generation of waste materials creates the most ecological problems for the environment. Especially e-waste materials are harmful and toxic waste materials compared to other solid waste. Selvam et al. (2015), studied the strength characteristics by conducting the tests on e-waste concrete with e-waste and the results revealed that up to $20 \%$ replacement e-waste for coarse aggregate in concrete shows improvement in compressive \& tensile strength. By comparing the results with conventional concrete at 28 days strength it is observed that the strength of concrete is reduced by $30.7 \%$ when coarse aggregate is replaced beyond $20 \%$ of e-waste. It is identified that e-waste can be disposed by using them as construction materials and the e-waste is not suitable to replace fine aggregate but it is used to replace the coarse aggregate. Also the compressive strength and split tensile strength of concrete containing e plastic aggregate is retained more or less in comparison with controlled concrete specimens. However, strength is noted to be decreased when the e plastic content was more than $20 \%$. And they have also concluded that, $20 \%$ of e-waste aggregate can be replaced as coarse aggregate replacement in concrete without any long term detrimental effects and with acceptable strength development properties.

Kumar (2018) studied the partially replacement of coarse aggregate with e-waste. He casted concrete cubes with 5\%, $7.5 \%$, and $12.5 \%$ e-waste and compared the compressive strength of M25 grade concrete with conventional concrete cubes of M25 grade. His study concludes that the electronic waste can replace coarse aggregate up to $12 \%$. It provides an effective way to disposal the e-waste. Makes the concrete light weight and thus the self-weight is reduced. Makes the concrete more flexible hence can easily bear the seismic loads. It reduces the stress on the natural resources. It increases the workability of concrete. Sustainable development is possible. It reduces the risk of harmness to land.

Prasanna \& Rao (2014) conducted the research on replacing the coarse aggregate with e-waste by $5 \%, 10 \%, 15 \%$ and $20 \%$ in one batch and they also made another batch with using same percentage of e-waste and also adding $10 \%$ of fly ash. The concrete strength is found out to be optimum when $15 \%$ of coarse aggregate is replaced with e-waste.

\section{E-WASTE CONCRETE}

Components of e-waste are Cathode ray tubes (used in TVs, computer monitors, ATM, video cameras, and more), a Printed circuit board (image behind the table - a thin plate on which chips and other electronic components are placed), Chips and other goldplated components, Plastics from printers, keyboards, monitors, etc., and Computer wires.

E-waste is defined as the type of concrete in which e-waste is used as the materials for concrete by partial replacement.

For solving the disposal of a large amount of recycled plastic material, the reuse of plastic in the concrete industry is considered the most feasible application. Recycled plastic can be used as coarse aggregate in concrete.

Objectives of this Experimental Investigation are (a) To identify e-waste that can be disposed of by using them as construction material. (b) Replacement of e-waste as coarse aggregate. (c)To limit the amount of toxic substances in certain electronic products. (d) To develop and improve the technology for e-waste management. (e) To reduce the pollution due to recycling of e-waste in the unorganized sec- 
tion. (f)To determine the compressive and flexural strength of concrete containing e-plastic aggregate.

\section{MATERIALS AND METHODS}

- Cement: Prozolona Portland cement, 53 grade conforming to IS: 455-1987 and other properties like finess,specific gravity etc., are pointed in Table 1.

- Fine aggregate: Locally available manufacturing sand conforming to grading zone II of IS: 383-1970

- Coarse aggregate: Locally available crushed blue granite stones conforming to a graded aggregate of nominal size $12.5 \mathrm{~mm}$ as per IS: $383-1970$.

- Tables 2 and 3 explain the properties of fine and coarse aggregate respectively.

- Water: Potable water

- E-waste used: Chipboard (plastic e-waste)

\section{E-waste}

In this experimental investigation, e-waste has been used as a partial substitute for coarse aggregate in concrete, that is high impact polystyrene (HIPS) plastic from all the electronic gadgets and its accessories are used in the concrete as a partial substitute for coarse aggregate in various percentages. In this present experimental investigation, a chipboard is used for e-waste.

\section{DESIGN AND METHODOLOGY}

Design Mix prepared based on Indian Standard Code of Practice and the below mix proportions were derived, are Shown in Table 4.

Table 1: Properties of cement.

\begin{tabular}{|lll|}
\hline S.No. & Property of Cement & Values \\
\hline 1 & Fineness of cement & $7.5 \%$ \\
2 & Grade of cement & 43 \\
3 & Specific gravity & 3.15 \\
4 & Initial setting time & $28 \mathrm{~min}$ \\
5 & Final setting time & $600 \mathrm{~min}$ \\
\hline
\end{tabular}

Table 2: Properties of fine aggregates.

\begin{tabular}{|lll|}
\hline S.No. & Characteristics & Value \\
\hline 1 & Type & M-sand \\
2 & Specific gravity & 2.68 \\
3 & Total water absorption & $1.02 \%$ \\
4 & Grading zone & II \\
\hline
\end{tabular}

\section{Mix Proportion}

Cement $=438.1 \mathrm{~kg} / \mathrm{m}^{3}$, Fine aggregate $=641.07 \mathrm{Kg} . \mathrm{m}^{-3}$, Coarse aggregate $=1120.827 \mathrm{Kg} \cdot \mathrm{m}^{-3}$, Water content $=197.16 \mathrm{~L} \cdot \mathrm{m}^{-3}$, Mix Ratio $=1: 1.46: 2.55: 0.45$

Mix Ratio = Cement: Fine aggregate: Coarse aggregate: Water

\section{EXPERIMENTAL INVESTIGATION}

\section{Slump Cone Test}

The slump test is a means of assessing the consistency of fresh concrete. It is used indirectly, as a means of checking if the correct amount of water has been added to the mix. The steel slump cone is placed on a solid, impermeable, level base and filled with fresh concrete in three equal layers. Table 5 shows the testes carried out on harded concrete after a curing period.

\section{Compression Strength}

The compressive strength of concrete is determined at the age of 7 days and 28 days. The specimens are cast and tested as per IS: 516-1959. The compressive strength of cubes is tested with a replacement of $10 \%, 15 \%$, and $20 \%$ of the mass of coarse aggregates with e-waste with selected quality of water. The tests are carried out on a 150x150x150 mm size cube, as per IS: $516-1959$. The test specimens are removed from the molds and unless required for the test within 24 hours, immediately submerge in clean fresh water and keep there until taken out just prior to the test. A $3000 \mathrm{kN}$ capacity standard compression testing machine is used to conduct the test. The specimen is placed between the steel plates of the compression-testing machine. The load is applied at the rate

Table 3: Properties of coarse aggregate.

\begin{tabular}{|lll|}
\hline S.No & Characteristics & value \\
\hline 1 & Type & Crushed \\
2 & Maximum size & $20 \mathrm{~mm}$ \\
3 & Specific gravity $(20 \mathrm{~mm})$ & 2.825 \\
4 & Total water absorption $(20 \mathrm{~mm})$ & $3.645 \%$ \\
\hline
\end{tabular}

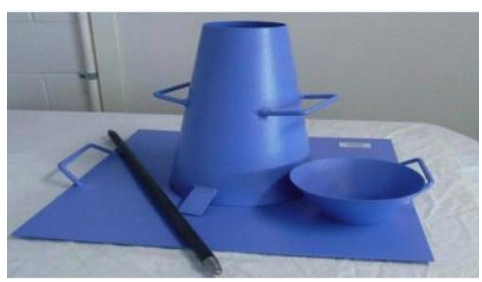

Fig. 1: Slump cone test. 
Table 4: Mix Proportion for a different mix.

\begin{tabular}{|lllllll|}
\hline Mix & $\begin{array}{l}\text { E-waste } \\
\%\end{array}$ & $\begin{array}{l}\text { Cement } \\
\left(\mathrm{Kg}^{-3}\right)\end{array}$ & $\begin{array}{l}\text { F.A } \\
\left(\mathrm{Kg}^{-3} \mathrm{~m}^{-3}\right)\end{array}$ & $\begin{array}{l}\text { C.A } \\
\left(\mathrm{Kg}_{\mathrm{m}} \mathrm{m}^{-3}\right)\end{array}$ & $\begin{array}{l}\text { E-waste } \\
\left(\mathrm{Kg} . \mathrm{m}^{-3}\right)\end{array}$ & $\begin{array}{l}\text { Mix proportion } \\
\text { (C: F.A: C.A: E-waste) }\end{array}$ \\
\hline M0 & 0 & 438.1 & 641.07 & 1120.82 & 0 & $1: 1.46: 2.55: 0$ \\
M1 & 10 & 438.1 & 641.07 & 1008.73 & 112.08 & $1: 1.46: 2.30: 0.25$ \\
M2 & 15 & 438.1 & 641.07 & 952.69 & 168.12 & $1: 1.46: 2.17: 0.38$ \\
M3 & 20 & 438.1 & 641.07 & 896.65 & 224.16 & $1: 1.46: 2.04: 0.51$ \\
\hline
\end{tabular}

Table 5: Test on hardened concrete.

\begin{tabular}{|llll|}
\hline S.No. & Type of Test & Properties studied & Size of the Specimen \\
\hline 1. & Compression Test & Compression Strength & $150 \times 150 X 150 \mathrm{~mm}$ \\
2. & Flexural Strength Test & Flexural Strength & $500 X 100 X 100 \mathrm{~mm}$ prism \\
3. & Split Tensile Strength Test & Tensile Strength & $150 \mathrm{~mm}$ diameter cylinder \\
\hline
\end{tabular}

of $140 \mathrm{~kg} \cdot \mathrm{cm}^{-2}$.min, and the failure load in $\mathrm{kN}$ is observed from the dial gauge of the compression testing machine.

\section{Flexure Strength Test}

The flexure strength of concrete was determined at the age of 28 days. The specimens were cast and tested as per IS: 516-1959. The compressive strength of cubes is tested with a replacement of $20 \%$ of the mass of cement with selected quality of e-waste, and $0.5 \%$ of the load shall be applied at a rate of loading of $400 \mathrm{Kg} \cdot \mathrm{min}^{-1}$ for the $15.0 \mathrm{~cm}$ specimens and at a rate of $180 \mathrm{Kg} \cdot \mathrm{min}^{-1}$ for the $10.0 \mathrm{~cm}$ specimens.

\section{Split Tensile Test}

The tensile strength of concrete is determined at the age of 28 days. The specimens are cast and tested as per IS: 516-1959. The compressive strength of cubes is tested with a replacement of $20 \%$ of the mass of cement with selected quality of E-waste, and $0.7 \%$ of CONPLASTSP-36 with selected quality of water. The load was applied continuously without shock at a rate within the range of 0.7 to $1.4 \mathrm{MPa}$. $\min ^{-1}$ (1.2 to $2.4 \mathrm{MPa} \cdot \mathrm{min}^{-1}$ based on IS 5816 1999). The breaking load is noted.

\section{RESULTS AND DISCUSSION}

The compressive strength result of the M25 grade of E-waste concrete trial mixes at the age of 7 and 28 days is tabulated in Table 6. The development of compressive strengths of M25 grade of e-waste concrete trial mixes containing 10\%, 15\%, and $20 \%$ coarse aggregate replacement level by fly ash and superplasticizer is added to the mixes.

All the mixes were tested at a period of 7 and 28 days. It is observed that the compressive strengths at the age of 28 days for M25 grade of e-waste concrete trial mixes containing $15 \%$ and $20 \%$ were 25 and $24 \mathrm{MPa}$ respectively; and at the age of 7 days were 18 and $17 \mathrm{MPa}$ respectively.

Table 6 presents the compressive strength of concrete mixes with and without e-plastic aggregates, where M0 is a conventional mix with $0 \%$ of e-plastic, M1 with $10 \%$ of e-plastic, M2 with $15 \%$ of e-plastic, and M3 with $20 \%$ of e-plastic. Graph $1 \& 2$ shows the graphical representations of compressive strength of all mixes M0, M1, M2, and M3 for 7 and 28 days. Hence, the maximum compressive strength was found to be 15 percent replacement of coarse aggregates by e-waste for M25 grades of concrete

Table 6: Compressive strength at 7 days and 28 days.

\begin{tabular}{|llll|}
\hline \multirow{2}{*}{ Mix } & E-Waste (\%) & \multicolumn{2}{c|}{ Compressive Strength (MPa) } \\
\cline { 3 - 4 } & & 7 days & 28 days \\
\hline M0 & 0 & 19 & 23 \\
M1 & 10 & 15 & 23 \\
M2 & 15 & 18 & 24 \\
M3 & 20 & 17 & 24 \\
\hline
\end{tabular}




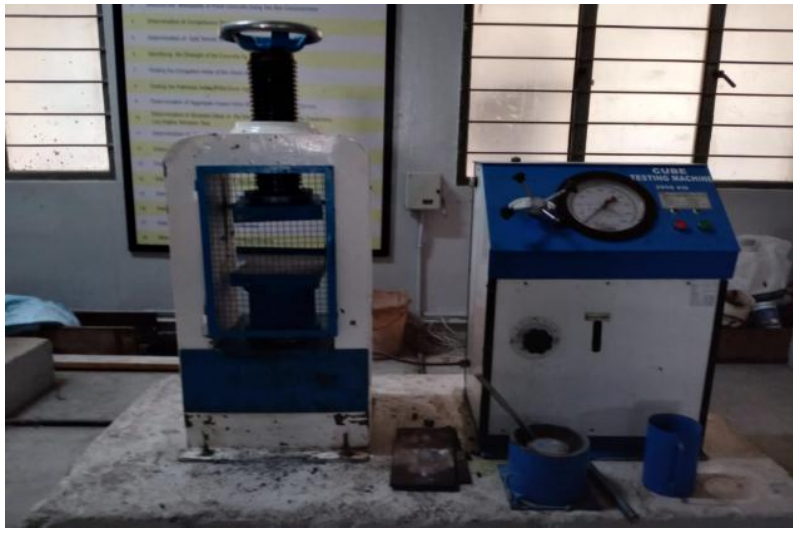

Fig. 2: Compressive strength test.

The results of the flexural test of e-waste concrete are given in Table 7. The influence of e-waste in concrete at different ratios is tabulated below.

All the mixes were tested at a period of 7 and 28 days. It is observed that the flexural strengths at the age of 7 days for M25 grade of E-waste concrete trial mixes for M0, M1, M2, M3, M4 were 2.65, 2.25, 2.59, and 2.43 Mpa respectively; and at the age of 28 days were $4.15,3.54,3.81$ and $3.63 \mathrm{MPa}$ respectively.

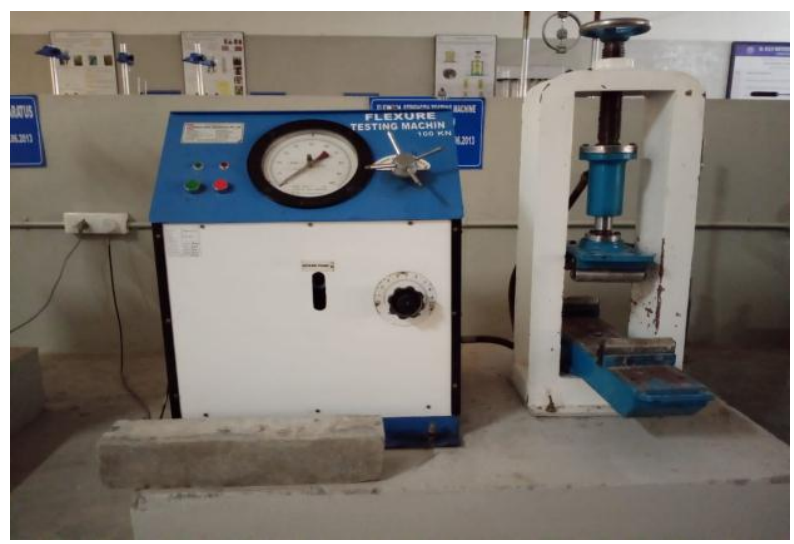

Fig. 3: Flexural strength test.

The experimental result for flexural strength is given in Table 7. All the mixes were tested at a period of 7 and 28 days. It is observed that the flexural strengths at the age of 7 days for M25 grade of E-waste concrete trial mixes for M0, M1, M2, M3, M4 were 2.4, 2.05, 2.31, and $2.26 \mathrm{MPa}$ respectively; and at the age of 28 days were $3.45,3.13,3.34$, and $3.28 \mathrm{MPa}$ respectively. From Table 8, the flexural strength is maximum when replacing $15 \%$ of coarse aggregate with e-waste in concrete. The development of tensile strengths

Table 7: Flexural strength at 7 days and 28 days.

\begin{tabular}{|llll|}
\hline \multirow{2}{*}{ Mix } & E-WASTE (\%) & \multicolumn{2}{c|}{ Flexural Strength (MPa) } \\
\cline { 3 - 4 } & & 7 days & 28 days \\
\hline M0 & 0 & 2.65 & 4.15 \\
M1 & 10 & 2.25 & 3.54 \\
M2 & 15 & 2.59 & 3.81 \\
M3 & 20 & 2.43 & 3.63 \\
\hline
\end{tabular}

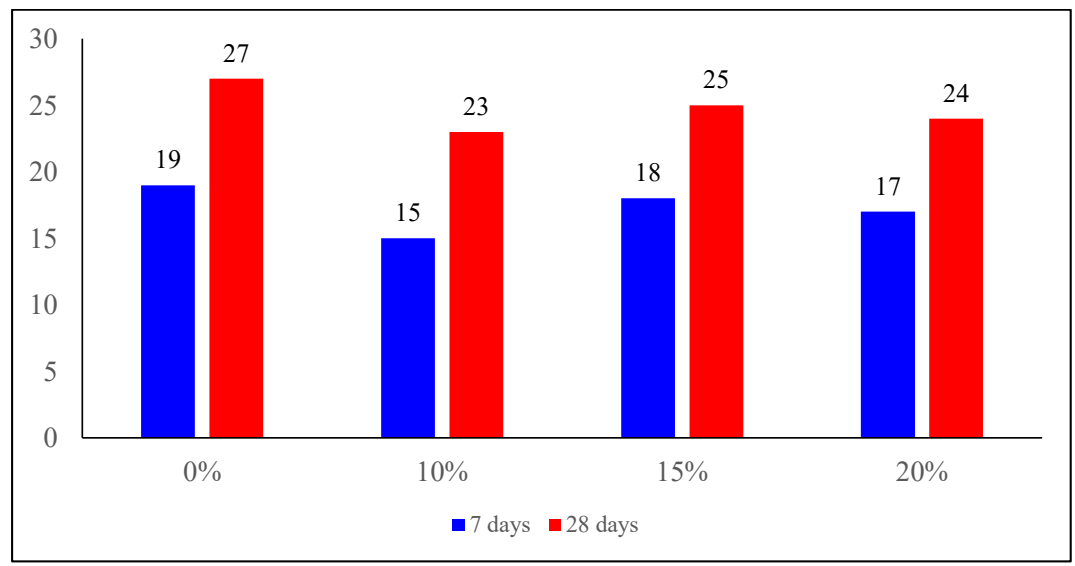

Fig. 4: Compressive strength of E-waste concrete at 7days and 28 days. 


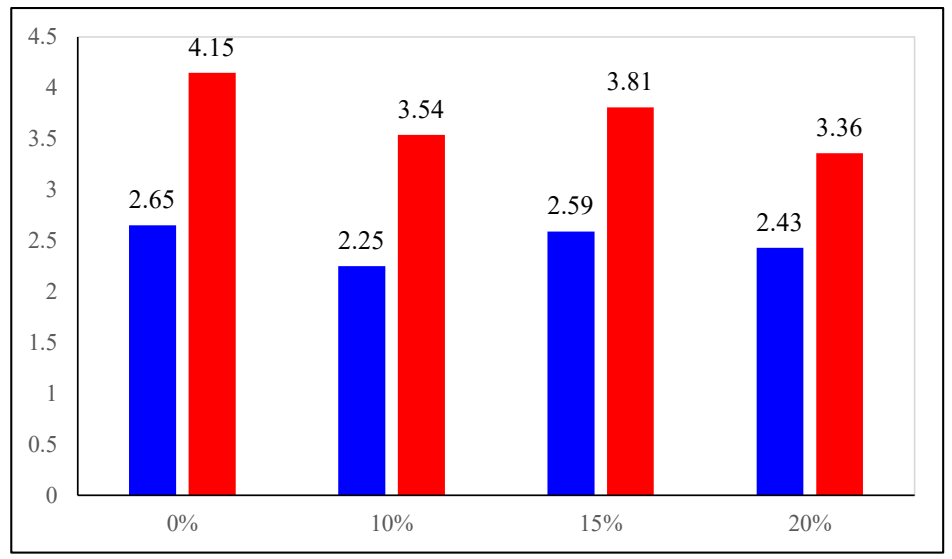

Fig. 5: Flexural strength of E-waste concrete at 7days and 28 days.

of M25 grade of concrete trial mixes containing 10\%, $15 \%$, and $20 \%$ replacement of coarse aggregates by e-waste and are relatively compared.

All the mixes were tested at a period of 7 and 28 days. It is observed that the tensile strengths at the age of 7 days for M25 grade of e-waste concrete trial mixes for M0, M1,
M2, M3, M4 containing $10 \%, 15 \%$, and $20 \%$ of e-waste were $2.4,2.05,2.31$, and $2.26 \mathrm{MPa}$ respectively; and at the age of 28 days were $3.45,3.13,3.34$ and $3.28 \mathrm{MPa}$ respectively

The experimental result for tensile strength is given in Table 8. From Table 8, the tensile strength is high when replacing $15 \%$ of coarse aggregate with e-waste in concrete.

Table 8: Tensile strength at 7 days and 28 days.

\begin{tabular}{|llll|}
\hline \multirow{2}{*}{ Mix } & E-Waste (\%) & \multicolumn{2}{c|}{ Split Tensile Strength (MPa) } \\
\cline { 3 - 4 } & 0 & 7 days & 28 days \\
\hline M0 & 10 & 2.4 & 3.45 \\
M1 & 15 & 2.05 & 3.13 \\
M2 & 20 & 2.31 & 3.34 \\
M3 & 2.26 & 3.28 \\
\hline
\end{tabular}

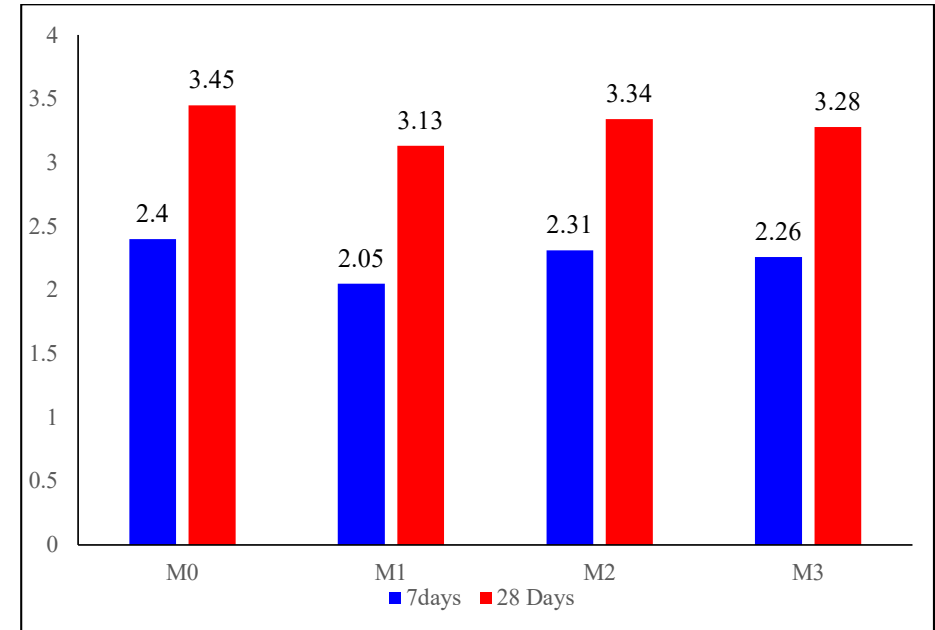

Fig. 6: Tensile strength of E-waste concrete at 7days and 28 days. 
From all the strength tests carried out on e-waste concrete, it is observed that the replacement of coarse aggregate by e-waste results in an increase in compressive strength, flexural strength and split tensile strength.

\section{CONCLUSION}

- Following are the conclusions that can be made based upon the studies made by various experimental investigations. E-waste plastics can be used to replace some of the aggregates in a concrete mixture. This contributes to reducing the unit weight of the concrete. This is useful in applications requiring non-bearing lightweight concrete.

- The effect of the water-cement ratio of strength development is not prominent in the case of plastic concrete. It is because the plastic aggregates reduce the bond strength of concrete. Therefore, the failure of concrete occurs due to the failure of the bond between the cement paste and plastic aggregates.

- For a given w/c, the use of e-waste plastics in the mix lowers the density, compressive strength, and tensile strength of concrete.

- The inclusion of recycled aggregates in the concrete of the buildings under investigation is shown to be advantageous from an energy point of view.

- As a result of the experimental investigation, it is well understood that e-waste can be used as an alternative for concrete making materials and it leads to less disposal of e-waste in the environment. Thus resulting in reduced pollution.

So, it can be concluded that e-waste can partially replace the coarse aggregates in concrete and it gives a sustainable solution to the natural resources like aggregates and reduction in the accumulation of e-waste. It also reduces the excess landfill due to the e-waste deposition. As a result, we can reduce pollution of the environment as the use of e-waste in concrete reduced its deposition in an open environment and thus reduce solid waste and its impacts.

\section{SCOPE FOR FUTURE WORK}

- E-waste material can be used instead of fine aggregates and strength can be verified.

- Along with e-waste some other chemical and mineral admixtures can be added and tested.

\section{REFERENCES}

Akram, A. 2017. E-waste management by utilization of e-plastics in concrete mixture as coarse aggregate replacement, Int. J. Innov. Res. Sci. Eng. Technol., 4(7), 24-39.

Balasubramaniam, B., Gopala Krishna, G.V.T. and Saraswathy, V. 2018. Review of literature on electronic waste materials used in concrete. Int. J. Eng. Manag. Res., 3(2): 31-35.

Kaniskha, N.B., Pavithran, P., Sanjai, J., Sheela, F. and Balaji, V. 2019. Study on concrete with e-waste as partial replacement of coarse aggregate and $\mathrm{m}$-sand as fine aggregate. Int Rese. J. Eng. Technol., 6(5): 2255-2265.

Kumar, Ankit 2018. Utilisation of e-waste in concrete by partial replacement of coarse aggregate. IEEE International Conference on Recent Advances in Engineering, Technology and Computational Sciences (RAETCS-2018) At: Sam Higginbottom University of Agriculture, Technology \& Sciences, Allahabad 05 Sep 2018.

Manjunath, A. 2017. Partial replacement of e-waste as coarse aggregate in concrete, Int. Conf. Solid Waste Manag., 35: 731-739.

Prasanna, P.K. and Rao, M.K. 2014. Strength variations in concrete by using E-waste as coarse aggregate. International Journal of Education and applied research, 4(2).

Raut, S.R., Dhapudkar, R.S. and Mandoakar, M.G. 2018. Experimental study on utilization of e-waste in cement concrete. Int. J. Eng. Sci., 23(19): 82-86

Selvam, N.P. and GVT, G.K. 2016. Recycle of E-waste in concrete. International Journal of Science and Research (IJSR), 5(4): 1590-1593. 